\title{
De sirenas tecnicizadas (II): lo mítico en 'La boina roja' de Rogelio Sinán
}

\author{
MARGHERITA CANNAVACCIUOLO
}

Università Ca' Foscari Venezia

\begin{abstract}
Resumen
El presente estudio constituye la segunda parte de un díptico crítico sobre 'La boina roja' (1954), el complejo relato de Rogelio Sinán. Tras haber desentrañado la construcción y el desarrollo de la línea narrativa relacionada con el saber 'y poder' de lo científico dentro de la ficción de Sinán en un estudio previo, el aspecto que el estudio indaga es la articulación del discurso del mito a partir y a través de la sirena. En el relato, la sirena funciona como figura revelada y reveladora ya que está pre-anunciada por un imaginario vinculado a la simbología acuática, y este entramado simbólico se puede desentrañar a raíz de su aparición. Paralelamente, la sirena desempeña un papel inter-medio en el relato, ya que se coloca entre dos espacios discursivos y de significación opuestos 'el de la ciencia y el del mito', a la vez que se configura como una instancia de mediación entre los mismos, que hace osmóticos los confines entre los dos ámbitos. La duplicidad de su representación icónica se refleja en la ambigüedad que caracteriza el discurso, que resulta dividido entre la perspectiva científica dominante del protagonista y la focalización cambiante del narrador en tercera persona que deja aflorar la retórica del mito.
\end{abstract}

\begin{abstract}
The present study is the second part of a critical diptych on the complex short story 'La boina roja' (1954) by Rogelio Sinán. The first part examined the relationship between the narrative and the power of science in the fiction of Sinán; this second part considers the articulation of the discourse of the myth starting from and through the function of the character of the mermaid. The study presents the hypothesis that in the story, the mermaid functions as a revealed and revealing figure, since it is announced by an imaginary linked to aquatic symbology, and this symbolic framework can be unravelled as a result of its appearance. The mermaid plays an intermediate role in the story, because it is placed between two opposing discursive spaces of signification, science and myth, at the same time as it is configured as an instance of mediation between them, which makes the confines between these two spaces osmotic. The duplicity of the mermaid's iconic representation is reflected in the ambiguity that characterizes a discourse divided between the mainstream scientific perspective on the protagonist and the changing focus of the third-person narrator that brings out the rhetoric of the myth.
\end{abstract}


... la isla, por ser maravillosa, casi parece irreal.

Por eso mismo necesito recrearla

para que pueda parecer verosímil.

Surgirá de improviso y, tras cumplir su objetivo, se volverá a sumir en la infinita vastedad de las aguas.

Rogelio Sinán, La isla mágica (1978: 651)

En diciembre de 1977, la serie de cinco programas, 'Ideas', de la Canadian Broadcasting Corporation $(\mathrm{CBC})$ transmite las conferencias tituladas Myth and Meaning, preparadas a partir de una serie de extensas conversaciones entre el antropólogo Claude Lévi-Strauss y Carole Orr Jerome, productora de la CBC, en la Universidad de Toronto. A la pregunta acerca de la relación entre ciencia y mito, el estudioso declara que 'ha habido un divorcio [...] entre el pensamiento científico y aquello que yo llamé la lógica de lo concreto, es decir el respeto por los datos de los sentidos y su utilización como opuestos a las imágenes, a los símbolos y a las cosas del mismo género' (Lévi-Strauss 1995: 34). El relato 'La boina roja' (1954) del escritor panameño Rogelio Sinán (1902-1994), objeto del presente estudio, se funda sobre ese 'divorcio' entre pensamiento mítico y científico, pero al mismo tiempo muestra la porosidad de los límites entre estos dos ámbitos, ya que se pone en escena la ilusoriedad del 'dominio de la naturaleza' por parte del pensamiento científico (Lévi-Strauss 1995: 41), a la vez que el aparente fracaso del mito en su objetivo de proporcionar al hombre un mayor poder material sobre el medio.

El profesor Ecker es un ictiólogo estadounidense de fama mundial que cumple una misión científica en Saboga, isla del trópico panameño, y tiene como asistente a Linda Olsen, muchacha de la boina roja, que había conocido en París. Los acompañan en su permanencia en la isla Ben Parker y el negro Joe Ward, dos ayudantes enviados por la Base estadounidense en Panamá, y la antillana Yeya encargada de ocuparse de la cabaña donde viven. A partir del enigma alrededor de la desaparición y supuesta muerte en mar de la joven, dos acontecimientos constituyen los nudos problemáticos de la historia: el niño que Linda da a luz en la isla 'que resultará ser una sirenita', y la progresiva metamorfosis de mujer a sirena que experimenta la joven.

El choque entre instancia narrativa homodiegética y heterodiegética insinúa la duda acerca de si ambos acontecimientos antes aludidos se deben a razones extrahumanas o extra-naturales 'característica de los relatos míticos de metamorfosis' (Calvino 2015) o si responden a razones biológicas. Se sugiere, de hecho, que el cuerpo de la joven se ha convertido en el objeto de observación del protagonista y su metamorfosis adquiere los tintes de una experimentación científica. Es aquí donde reside la ambivalencia genérica del cuento que linda con la ciencia ficción.

Con respecto al título del estudio que aquí se propone, me apropio del adjetivo 'tecnicizado' utilizado por Karoly Kérény (1964) en 'Dal mito tecnicizzato al mito genuino' y que será retomado por Furio Jesi en Letteratura e mito (2002: 36); en ambos trabajos con ese sintagma se entiende un mito o materiales míticos evocados adrede y manipulados para un fin determinado, en especial político, en 
contraposición con el 'mito genuino', el cual es espontáneo y desinteresado. ${ }^{1}$ En el presente estudio, utilizo el adjetivo ‘tecnicizado', sin embargo, ya no en el sentido de evocación del material mítico 'evocación que se da en cualquier texto literario que se apropia de un mito extra-literario o en los discursos del poder que asumen la retórica del mito', sino que me refiero a la producción o reproducción ex nihilo de la sirena dentro de la historia. La tecnicización se asocia a las dos sirenas evocadas en el texto porque estas no aparecen in flagranti dentro de la narración, como imágenes míticas ya dadas 'que afloran de las profundidades de otro tiempo y otro espacio', sino que en cierta medida se presentan como productos 'manipulados' por un pensamiento y una techne científica. ${ }^{2}$

El presente estudio constituye la segunda parte de un díptico crítico sobre este complejo relato de Rogelio Sinán. Tras haber desentrañado la construcción y el desarrollo de la línea narrativa relacionada con el saber 'y poder' de lo científico dentro de la ficción de Sinán en un estudio previo (Cannavacciuolo 2017), el aspecto que aquí me interesa indagar es la articulación del discurso del mito a partir y a través de la sirena. Mi hipótesis es que en el relato, la sirena funciona como figura revelada y reveladora (Kerényi 2017: 29), ya que, por un lado, está pre-anunciada por un imaginario vinculado a la simbología acuática; ${ }^{3}$ y, por el otro, este entramado simbólico se puede desentrañar a raíz de su aparición. Paralelamente, la sirena desempeña un papel inter-medio (Bhabha 1994: 12) en el relato, ya que se coloca entre dos espacios discursivos y de significación opuestos 'el de la ciencia y el del mito', a la vez que se configura como una instancia de mediación entre los mismos, que hace osmóticos los confines entre los dos ámbitos. La duplicidad de su representación icónica, de hecho, se refleja en la ambigüedad que caracteriza el discurso, que resulta dividido entre la perspectiva científica dominante del protagonista y la focalización cambiante del narrador en tercera persona que deja aflorar la retórica del mito.

\section{La poética de Sinán: una mirada al sesgo}

Antes de adentrarme en el análisis propuesto, me parece interesante colocar 'La boina roja' dentro del rumbo de la literatura panameña del periodo y de la cuentística del autor. Junto con Roque Javier Laurenza (1910-1984) y Manuel Ferrer Valdés (1914-1977), Rogelio Sinán pertenece a la primera generación de los escri-

1 'Kerényi ha insistido siempre, precisamente para recalcar la cualidad benéfica de la mitología, en la distinción entre mito genuino y mito tecnicizado: entre mitología genuina, vale decir espontánea y desinteresada elaboración de los "contenidos" que afloran espontáneamente de la psique, y mitología tecnicizada, evocación y elaboración interesada de materiales que pueden servir a un fin determinado. En las doctrinas de la "derecha tradicional" acerca del mito como substancia metafísica, ha señalado Kerényi "una tecnicización de la mitología”' (Jesi 1976: 101).

2 En el primer caso, Linda da a luz una sirenita que sería generada por la fecundación del ovocita femenino por parte del semen de un pez macho, y, en el segundo caso, la joven misma sufre una metamorfosis psicológica y física, tal vez inducida por el anhelo científico de Ecker.

3 Véase Bachelard 2005, 2012; Durand 2004; Libis 2004. 
tores más representativos de una tendencia estética de claro signo renovador que reacciona contra el realismo mimético imperante en el cuento panameño. ${ }^{4}$ Con la aparición de 'El sueño de Serafín del Carmen’ (1931), primer cuento de Sinán, se manifiesta una nueva tendencia que Rodrigo Miró califica como 'empresa esteticista que trata de universalizar nuestro ambiente literario, renovando la técnica y ensanchando horizontes' (1999a: 29).

'La boina roja' marca, según Gloria Guardia (1974: 19), el tercer gran momento de creación del autor dentro del género, precedido por una primera etapa vanguardista con el poemario Onda (1929) 'escrito en Roma y de allí enviado a Panamá (Sinán 1983)' y con el cuento 'El sueño de Serfín del Carmen’ (Panamá, 1931); y por una segunda etapa de marcada estética constructivista con el relato 'A la orilla de las estatuas maduras' (París, 1932). De todas las características del estilo del autor subrayadas por la crítica, sobresalen en este relato la creación de ambientaciones naturales mágicas o superrealistas a través del tríptico mundo psíquico, ambigüedad y naturaleza de índole vital; la voluntad de conciliar universalidad y especificidad, ya que la geografía declaradamente panameña es teatro de una situación de índole cosmopolita; y la capacidad de creación fuera del círculo inmediato de las experiencias del autor, lo cual se nota en la elaboración del personaje del biólogo Paul Ecker y en la descripción minuciosa de sus actividades ictiológicas. ${ }^{5}$ A todo esto se añade la presencia del elemento mítico, vinculado al polisémico imaginario acuático o al sueño y a la ensoñación, y la presencia conflictiva del elemento afro-antillano, como rasgos recurrentes y característicos de la cuentística del autor compartidos también por el relato que aquí se considera.

Los personajes míticos o del folklore pululan en los cuentos de Sinán, a menudo asociados al agua, o al mundo onírico del cual entran y salen, como en el caso de la ya citada opera prima del autor 'El sueño de Serafín del Carmen', donde el personaje soñador, ya cubierto casi del todo por las aguas del lago en el que se encuentra, reconoce en 'la muchacha de los ojos verdes' a la diosa Anfitrite (Sinán 1998: 9), antigua diosa del mar tranquilo, esposa de Poseidón y madre de Tritón. ${ }^{6}$

'A la orilla de las estatuas maduras', en cambio, se abre con la imagen del río -'Allí en el río era donde mejor estaba' (1998: 11)-, en cuya orilla el chico protagonista encontrará a las tres chicas desnudas quienes, como tres modernas Gracias, juegan a flor de agua. Si el río representa para el protagonista el lugar de juego y descubrimiento de la primera sensualidad, el agua y sus secretos se convertirá

4 Véase Miró Grimaldo 1999a: 22-37; y García de Paredes 1999. Los dos volúmenes, publicados por primera vez respectivamente en 1950 y en 1998, se publican juntos en un mismo volúmen en 1999 (añadir 'en un mismo volúmen'), edición que se toma en consideración en el presente trabajo.

5 Prueba ulterior del estudio de profesiones y situaciones foráneas a las experiencias vitales del autor llevarán también a la creación del personaje del psicoanalista Serge en 'Todo un conflicto de sangre', y del cirujano plástico en 'El cirujano del cielo' y el fotógrafo en 'Hechizo'. Los tres cuentos citados y los que se citarán a continuación están contenidos en Sinán 1998.

6 En este cuento, el atributo cromático de los ojos de la muchacha parece ser una referencia intertextual al epíteto de Anfitrite en la tradición mítica, vestida con una armadura color verde. 
en la obsesión del cura del pueblo, para el cual las olas configuran una 'geografía infernal' (20), ya que en ellas ‘se movían [...] se cruzaban, las líneas dóciles ¡Anclas, piernas y senos de mujeres!' (20).

En 'La única víctima de la revolución', la joven Laura, hermosa hija de una familia pobre, puede aceptar y entregarse a la pasión amorosa que el viejo y rico don Pepe siente por ella, comparando su historia con la de Júpiter y Danae, y transfigurando la riqueza de él en 'una lluvia de oro' que caerá sobre su cuerpo (23). Una vez más, el agua ‘sabrosa’ (26) del baño que la chica se da antes de su cita, le alivia su destino hasta el olvido. Una 'lluvia infernal, con truenos, relámpagos y cataratas de agua’ (44), además, sirve de escenario para el sueño prohibido del protagonista de 'Hechizo'.

Otro elemento recurrente en la poética del autor es la dicotomía entre lo autóctono y lo foráneo, ya que, a menudo, se alude a lo africano y a lo antillano como cuna de lo ominoso y, por esto, considerado elemento marginal de y marginado por la sociedad, objeto de discriminación por los protagonistas extranjeros. En 'Todo un conflicto de sangre', la rica señora Rosemberg admite a su servicio a un chofer antillano, no sin resistencias ya que 'no le agradaban mucho los negros [...] Más bien los despreciaba’ (91). La música afrocubana acompaña a la protagonista de 'La única víctima de la revolución', y alivia la pena de su forzada cita amorosa; y en 'Lulú ante el tribunal', los negros son los perreros temidos encargados de liberar las calles de los perros sin placas. Estas referencias confluyen en la repulsión y el asco que Linda siente contra la antillana Yeya en 'La boina roja' (115), de la cual, además, se dice que 'es vejancona. Le dicen “la Vudú”. Habla una jerga rara, pero entiende el inglés' (114).

Dimensión onírica y 'realidad' constituyen dos vasos comunicantes que se alimentan mutuamente en las historias, lo cual determina la ambigüedad característica de los relatos de Sinán. Los sucesos acaecidos en los sueños a menudo producen una interferencia en la vida de los protagonistas, o bien sus obsesiones en la vida real pasan a poblar sus pesadillas, determinando así que para ellos los límites entre sueño y realidad se hagan cada vez más dudosos y borrosos.

La pesadilla es la prisión sin paredes en la que es cautivo el protagonista de 'Hechizo' por haber deseado a una joven; mientras que en el ya citado 'Todo un conflicto de sangre', las pesadillas de la protagonista advierten de su inminente locura y, desde el punto de vista narratológico, constituyen el elemento que determina la interrupción de un régimen descriptivo y desencadena el movimiento narrativo. ${ }^{7}$

7 La alemana y racista señora Rosemberg, fanática de la raza aria, tras ser expulsada por la boca de un negro gigante, sueña con dirigirse hacia una montaña donde la espera Cristo, quien, en lugar de ser 'un Mesías magro y doliente', se le presenta como 'un negro fornido' (Sinán 1998: 95). Al despertarse, la mujer sigue oyendo las mismas risas inquietantes que animaban su pesadilla y, al preguntar a su criada, se entera de que se trataba de su chofer antillano, en cuya cara le parece reconocer al negro del sueño. Al relatar su sueño al psicólogo, la protagonista afirma: 'Algunas horas después, cuando fui a entrar al auto, vi la cara sonriente del antillano, y parecióme notar que me miraba con cierta picardía ... Parecerá algo absurdo, pero la cara de él era la misma que había visto en mi sueño' (1998: 96). En su 
El sueño puede servir como motor narratológico de la historia, como en los cuentos aludidos, o, también, los sucesos se apelan como sueños para disfrazar hechos difíciles de aceptar. Este es el caso de 'Ninguna novedad en Shangai', donde el recurso al sueño les sirve a los pasajeros de un transatlántico rumbo a Shanghai para aceptar y pasar por encima del asesinato de una pasajera china.

Materiales mitológicos, rêverie acuática, contaminación entre sueño y 'realidad', y presencia de lo negro confluyen y determinan temática y estructuralemente las historias narradas, llegando a construir un intrincado entramado intertextual dentro de la obra del autor.

\section{Pre-figuración y revelación}

'La boina roja', objeto de nuestro estudio, se inserta dentro de una larga tradición literaria hispanoamericana vinculada al tema de la sirena. ${ }^{8}$

segundo sueño, la hostilidad de la mujer hacia lo africano se transfigura en un desordenado baile de negros liderado por el mismo Joe, cuyo ritmo mágico contamina a la protagonista llevándola a 'hacer cabriolas y dar brincos, presa de cruel insania ... ' (96), y el autista será el protagonista también de su tercer y cuarto sueño. En el desenlace del relato, la presencia obsesiva de su chófer antillano Joe en las contrucciones oníricas de la señora Rosemberg se explica por el hecho de que la mujer se entera de que Joe ha sido el donador de la sangre que la ha salvado de la muerte.

8 En la literatura mexicana, el tema de la sirena ha sido explorado copiosamente por Antonio Acevedo Escobedo en el cuento 'Sirena en el aula' (volumen homónimo 1935), Guadalupe Dueñas en 'Al revés' (Tiene la noche un árbol 1958), y por Luis Córdova en el relato 'La sirena precisa' (volumen homónimo 1960); también Inés Arredondo sugiere la imagen de la sirena en la protagonista femenina del cuento 'Wanda' (Los espejos 1988). En la producción más actual, destacan también La comunión de la sirena (2000) de Víctor Hugo Rodríguez Béquer, el cuento 'El hombre que siempre soñó' de Cristina Rivera Garza (Ningún reloj cuenta esto 2002), el relato 'De sirenas a sirenas' (2010) de René Avilés Fabila, contenido en el volumen homónimo de relatos y microrrelatos, en la sección 'Breviario mitológico'; y el volumen Sirenidades (2011) de Augustín Monreal. En ámbito teatral, el tema de la sirena se explora en la pieza La sirena que llevaba al mar (1951) de Magdalena Mondragón. En el contexto mexicano, además, dicha figura mítica ha sido objeto de atención no sólo de los autores, sino también de los antologadores. Este es el caso de la antología Relatos vertiginosos (2001) a cargo de Lauro Zavala, donde aparece la sección 'Las sirenas; o de los volúmenes de Javier Perrucho enteramente dedicados al tema Yo no cuento Ulises, canto (2008), y La música de las sirenas (2013). En la literatura venezolana, están dedicados a la sirena los poemas narrativos 'Visión del norte', 'La cuestación', 'Mar latino', 'El musulmán' y ‘Rapsodia' de José Antonio Ramos Sucre (Las formas del fuego 1929). Por otra parte, en la literatura argentina la mujer de agua tiene su representación entre otros en La sirena (Tríptico 1908) de Carlos Octavio Bunge, 'Sirenas' de Jorge Luis Borges (Manual de zoología fantástica 1957), 'Silencio de sirenas' (Falsificaciones 1966) de Marco Denevi, 'La sirena en el arca' de Eduardo Gudiño Kieffer (Fabulario 1969), 'La sirena' de Rodolfo Wilcock (Lo stereoscopio dei solitari,1972), 'Unas y otras sirenas' de Luisa Valenzuela (Donde viven las águilas 1983), ‘Sirenas?' de Ana María Shua (La sueñera 1984), e 'Y así sucesivamente' (volumen homónimo 1987) de Silvina Ocampo. El crítico argentino e historiador de la microficción hispánica David Lagmanovich también se ha dedicado al tema en 'La sirena', 'Sirenas emigrantes' y ‘Otra sirena' (Los cuatro elementos 2004). En poesía cabe mencionar 'La sirena violada' (volúmen homónimo 1957) de Juan José Ceselli, mientras que en las producciones literarias argentinas más reciente destaca La Sirena de Oxford St. y otros cuentos (1991) de Santiago Galli y el cuento 'El hombre sirena' de Samantha Schwe- 
Escrito durante su estadía en México y publicado en 1954, el relato se convierte en uno de los cuentos de Rogelio Sinán más conocidos, representativos y galardonados. Obtiene el Primer Premio en el Concurso Interamericano de Cuento de El Nacional de México en el mismo año, y es seleccionado para la antología de los mejores cuentos de este país y Centroamérica que editaría el OPIN (organismo creado por el gobierno de México para la difusión de la cultura). En 1964, Seymour Menton lo incluye, desde la primera edición, en su célebre antología El cuento hispanoamericano, publicada originariamente en el Fondo de Cultura Económica el mismo año (véase Menton 1980). ${ }^{9}$

A partir del presente de la narración, constituido por el interrogatorio de Paul Ecker a cargo de un juez a raíz de la desaparición en mar de Linda Olsen, el relato se divide en dos líneas narrativas analécticas que se entretejen y dan dos versiones distintas y complementarias de la historia. La primera es el relato homodiegético a cargo de Ecker acerca de su vida en la isla y de la conducta de Linda. La segunda 'que se presenta entre paréntesis y en cursiva' es una instancia heterodiegética que da al lector diferentes detalles de la historia, y arroja luz sobre hechos omitidos por el profesor. Además, la presencia, a momentos, del discurso indirecto libre y de la psiconarración le confiere, a este segundo nivel, los rasgos de una rememoración interna, porque no está declarada, del protagonista. La modificación de las letras en el pasaje de una instancia a la otra configura los dos discursos como dos cuentos en uno, que brindan, de manera cubista, dos visiones simultáneas del mismo hecho. ${ }^{10}$

En la primera parte de la historia, se describe el primer encuentro entre Paul Ecker y Linda Olsen, su vida en la isla, los estudios del profesor de la vida erótica de los peces y la actitud seductora que Linda tiene hacia Ben y Joe, rasgo que ya deja entrever el legado nefasto de las sirenas homéricas y post-homéricas.

blin (Pájaros en la boca 2010) y la novela Las puertas de Cassiopea (2012) de Rosalba Campra. Asimismo, en la literatura uruguaya, Mario Benedetti ha recreado dicha figura mítica en las narraciones 'La sirena viuda' y 'Un reloj con números romanos' (Despistes y franquezas 1989), y Eduardo Galeano la hizo propia en 'Sirenas' (Bocas del tiempo 2004). También el chileno Juan Armando ha encarado el tema en el microcuento 'La Pincoya' (Para leerte mejor 2010); mientras que el narrador peruano Ciro Alegría incluyó 'La sirena del bosque' entre sus Fábulas y leyendas americanas (1982). Hay que señalar también el poemario Cuba, sirena dormida (1991) del cubano Evelio Domínguez y el volumen de cuentos infantiles La sirena de los pescaditos (1984) del costarricense Rafael Valle Heliodoro.

9 Se señala, también, la presencia de 'La boina roja' en la antología a cargo de García de Paredes, Franz, 1998. Panamá: cuentos escogidos (Panamá: Autoridad del Canal), pp. 258-80; no aparece, en cambio, en la edición citada de 1999, donde figura 'A la orilla de las estatuas maduras' (pp. 108-19). Con poemas escogidos de Rogelio Sinán se abre la sección 'La poesía nueva. Los vanguardistas', con la cual empieza el segundo tomo de Itinerario de poesía en Panamá a cargo de Rodrigo Miró (Panamá: Autoridad del Canal), pp. 3-21. Para un más detallado recorrido a lo largo de todas las referencias a la obra de Rogelio Sinán, remito a la nota introductoria sobre el autor en Menton 1980: 3-4). 'Hechizo', a su vez, fue escogido por Eduardo Mallea para un volumen que La Nación de Buenos Aires dedicó a los mejores cuentistas americanos. También el crítico chileno Ricardo Latcham lo incluyó en una antología de cuentos iberoamericanos.

10 La brillante intuición de una perspectiva cubista que rige el relato se debe a Menton 1980: 317. 
Tras enterarse de que el biólogo iba a estudiar los peces al Archipiélago de las Perlas, la joven lo busca para pedirle ser su asistente: ‘Qué maravilla!... ¡Pasar un año entero disfrutando del Trópico, del mar, del sol, del aire, libremente y en íntimo contacto con la Naturaleza!...j Tiene usted que llevarme! [...] ¡Sí, sí, no he de negarle que recibí una oferta de John Hamilton! ... ¡Qué ofensa! ¿Se imagina? Yo, asistente de un hombre de color ...' (Sinán 1998: 112). Lo que se nota de las palabras de la protagonista que se acaban de citar es cierta idea, asumida por el discurso, de exotismo estereotipado que la cultura hegemónica exterior tiene sobre lo panameño identificado genéricamente con lo tropical, el mar, el sol y el aire libre. El rechazo a lo negro declarado por Linda se remata, además, en cierta 'desconfianza' que ella siente contra la vieja, 'una especie de repulsión, de asco' (1998: 115). ${ }^{11}$

Cuando Linda acusa al negro Joe de haberla violado, este por miedo huye con Ben a la Base, y la joven le pide a Ecker que no dé la alarma por miedo a que el abuso provoque un escándalo que pudiera perjudicarla. Ya solos en la isla, crece la intimidad entre Linda y Ecker; es entonces cuando la joven descubre que está embarazada. Según admite Ecker al juez, lo que Linda da a luz, 'Era una cosa deforme, muerte, fofa ... Temiendo que Linda Olsen pudiera darse cuenta al despertarse, corrí bajo la noche aún tempestuosa y eché el engendro al mar; así borraba toda huella o vestigios de su fealdad' (120). A esta declaración oficial le corresponde otra versión de lo ocurrido a cargo de la instancia en tercera persona:

Esa noche [...] surgió el raro misterio ... Vió una carita fina, muy tierna, sonrosada, y unos bracitos tersos impecables ... [...] [Ecker] ya anhelaba recibir en sus manos a la criatura y sentirla suya, perfecta y sana, cuando aquello saltó, dió un coletazo y rebotó sobre el lecho [...] Lo que bullía frente a él, sobre las sábanas, era un mito viviente: un pez rosado como un hermoso barbo, pero con torso humano, con bracitos inquietos y con una carita de querubín... Aquella cosa de rasgos femeninos tenía todo el aspecto de una sirena ... [...]. (Sinán 1998: 123-24; las cursivas en el original)

La alusión genérica del ictiólogo a una 'cosa deforme y fofa' (120) deja lugar a la detallada descripción de una sirena en las palabras del narrador en tercera persona. Frente a la pérdida de vitalidad de la criatura, el protagonista la sumerge en las aguas, y ésta con un coletazo se libera y huye. A partir de la desaparición de su hijo, cuya condición de sirenita ignora Linda, la joven empezará a sufrir una atracción por el mar, paralelamente a una progresiva metamorfosis en sirena que la llevará al hundimiento definitivo en las aguas.

Según Kerényi (2017: 225), con el término 'figura' se entiende algo que no tiene el rasgo visual de las imágenes, sino más bien una idea, que como tal está constituida por una 'materia fluida', y que se origina también del conjunto de unas imágenes. Parafraseando al filósofo, entonces, podríamos afirmar que a partir de la epifanía de la sirena, ésta en cualidad de figura se va dibujando gracias a

11 A este rechazo le corresponde la descripción que se hace de Yeya y su aislamiento con respecto a los protagonistas. De ella, además, Ecker declara que 'vivía distante de nosotros, y poco la veíamos; sobre todo porque pasaba el tiempo pescando en alta mar' (Sinán 1998: 118). 
un conjunto de imágenes que vehiculan un simbolismo ictiomorfo y, al mismo tiempo, el agua servirá de tejido conectivo entre ellas. Las alusiones a las piernas unidas, a la viscosidad de la piel y las referencias al engullimiento, elementos que, como se verá, se insertan dentro del vínculo cada vez más intenso entre la joven y el agua.

Tras la pérdida de su hijo, se establece una correspondencia vital entre el elemento acuático y la conciencia desdichada de Linda. La atracción que la mujer siente por el abismo de transparencias deleitables provoca, en palabras de Ecker, un 'afán constante de chapalear entre las ondas [...] tan intenso, que a veces levantábase del lecho, sonámbula, y, desnuda, se dirigía a la playa a grandes saltos... Estos diversos síntomas me fueron indicando su fatal propensión en convertirse en sirena...' (Sinán 1998: 126). En sus sueños nocturnos, Linda se ve rodeada por monstruos pisciformes y tritones y, durante el día, a esto le corresponde la viscosidad cada vez más acentuada de la piel y cierta parálisis de las piernas, 'unidas como si algo invisible les impidiera su ritmo individual' (1998: 128), así como la nauseabunda costumbre de alimentarse con moluscos vivos. A este respecto el ictiólogo relata: 'Su gran voracidad no hacía distingos entre algas, y babosas ... La vi engullir medusas a mordiscos con la fruición de quien deglute moldes de gelatina...' (125-26).

Las líneas que se acaban de citar introducen, además, otro aspecto fundamental en la configuración de la sirena, es decir, la cadena de engullimientos que se construye alrededor del personaje de Linda, esquema característico del simbolismo del pez según Gilbert Durand (2004: 52 y ss.). Linda ‘engulle’ metafóricamente a los hombres que seduce, traga materialmente a algas y medusas; al mismo tiempo, el océano, 'supremo devorador', engullirá a Linda, y, a su vez, la isla en la que se desarrolla la acción se configura como una especie de 'Jonás' geográfico según Durand, engullida por las aguas que la rodean. En este sentido, es posible también apuntar al carácter paradójico, inherente a la ‘figura’ según Kerényi (Kerényi 2017: 225 y ss.), de la sirena Linda: ella es deseante y deseada, seductora de los hombres que la rodean y seducida por la Naturaleza, a la vez que engullidora y engullida por las aguas.

La figura de la sirena resulta, por lo tanto, revelada por las imágenes que la sostienen, a la vez que reveladora, porque trabaja también como 'principio formativo (invisible)' indicador de las mismas (Kerényi 2017: 226). Un tejido narrativo de alusiones simbólicas preanuncia y confluye en el nacimiento de la sirenita y la metamorfosis de Linda; al mismo tiempo, la aparición de las dos sirenas arroja luz a posteriori sobre dicha red, ya que la narración se organiza en función de su revelación. Como figura, la sirena es, por lo tanto, el principio organizador que marca el sentido de la trama, en ambos significados de la feliz polisemia del término, de dirección y significado.

A raíz de lo afirmado, es posible volver a leer el cuento, rastreando las huellas prefiguradas por la sirena, y que contribuye a delinear y diseminar su figura dentro de la narración.

En la primera aparición de Linda Olsen, rememorada por Paul Ecker, la descrip- 
ción que se da de la joven refleja algunos rasgos que caracterizan a las sirenas mitológicas: 'La Sorbonne! ... Sí, allí la conoció ... Tenía el aspecto de una inocente colegiala pero iqué embrujadora! ... Lo que más lo sedujo fue su faldita azul marino y aquella boina roja levemente ladeada sobre una sien...' (Sinán 1998: 111; las cursivas en el original). El azul marino de la falda, así como la asociación que se establece entre seducción y hechizo remite a la constancia icónica de las sirenas homéricas y post homéricas; a su localización 'el mar' así como a su característica más reconocida y repetida en todas las versiones de los relatos míticos que las ven protagonistas, es decir, el poder de atraer a los hombres que encuentran.

Más adelante, Ecker refiere que la joven, 'en pleno goce de su adolescencia, languidecía de hastío ... A veces nos seguía coleccionando conchas y caracoles, pero más le agradaba vagar entre los árboles. Y era que, sin nosotros, no quería estar sola en casa, porque sentía no sé qué [...] de vago presentimiento' (1998: 115). La acción de coleccionar conchas y caracoles participa de la cosmogonía del agua y del simbolismo relacionado con la mujer y su fertilidad, a la vez que el impulso hacia estos se reviste del presentimiento que anticipa la metamorfosis que le acontecerá a Linda.

Al mismo tiempo, la referencia a las conchas recogidas por Linda vuelve amplificada en la imagen de un 'gigantesco caracol' (132) que cierra el relato, símil del alma de Ecker dentro de la cual resuena el canto de Linda:

¿Cómo llegué a la playa? No lo sé. A lo mejor anduve perdido entre las rocas hasta caer rendido sobre la arena. Lo cierto es que al volver de mi colapso ya el alba despuntaba y había amainado la tormenta, pero yo seguía oyendo dentro de mí el eco lejano de aquel canto mezclado a la honda resonancia del mar como si mi alma entera se hubiese transformado en un gigantesco caracol ... (Sinán 1998: 132)

Tras su peripecia en el océano en búsqueda de su asistente, Ecker vuelve cambiado a la vida desde y por parte del agua; dentro de él se ha insidiado un misterio que ha puesto en duda su seguridad de carácter científico acerca de la realidad. Su actitud racionalista y positivista ha sido fecundada por el germen del misterio mítico del origen.

En esta imagen, el simbolismo de la concha aparece invertido, ya que es el protagonista varón el que se identifica con el caracol, lo que sugiere su fecundación metafórica por parte de la mujer-sirena, a la vez que la fecundación que sufre su memoria, que se convierte en depósito de la historia que se cuenta. De la misma forma en que la concha recubre al molusco protegiendo su materia, 'fina imagen de la existencia' (Bachelard 2012: 141), Ecker, como sobreviviente, se convierte en morada y fortaleza del secreto de Linda y de su incierto destino, un secreto que él mismo ignora y es incapaz de comunicar. Ecker sigue oyendo dentro de sí el canto lejano y el sonido del mar porque se han convertido en su sustancia obsesiva, de la cual ya no se puede desprender; de la misma manera en que el caracol depende del molusco que lo produce, Ecker depende del canto de Linda y del misterio de su contenido. 


\section{Entre amor y muerte, el agua}

La figura de la sirena en el texto, tanto en su anticipación como en su revelación, se inscribe dentro de la presencia constante del agua y del vínculo cada vez más intenso que la protagonista establece con el mar.

El agua participa en la narración de manera constante y polimorfa: es el espacio ritual del baño, la cuna erótica en el momento del amor, la fuente que brinda la vida y el remolino que la quita. Al mismo tiempo, sufre un proceso de transformación gradual de presencia afrodisíaca que rodea los juegos de amor de los personajes en la isla a protagonista de una erotización ejercida y sufrida.

El mar, en particular, aparece como el teatro de dicha erotización, dado que la fascinación que Linda siente por él está completamente involucrada en un proceso de deseo con una doble polaridad; confusional y regresiva. El ritual del baño en el mar acaba por llenar casi por completo el tiempo de la joven durante el embarazo, confiriéndole el doble rasgo, neurótico y lujurioso, de una pulsión regresiva. De hecho, la histeria de Linda solo se aplaca cuando el profesor la sumerge en el mar y a la hora de comer Linda no advierte hambre, pero poco después Ecker la encuentra devorando mariscos a orillas del mar:

[S]intiéndose agotada y ya frenética, se echó al suelo, gritando, poseída por un ataque de histeria ... Me apresuré a atenderla y, al acercármele, noté que se asfixiaba por falta de aire. [...] pensé que lo más cuerdo sería llevarla al mar ... Así lo hice, corriendo, y, al chapuzarla, me quedé sorprendido ... Linda reía feliz como si nada y hacía raros esguinces chapaleando con las piernas unidas. Ya no dudé que el mar, siendo la causa, podía ser el remedio de su trastorno ... Sólo hundiéndose en él podía salvarse, si era que en esa lucha no era el mar quien vencía hasta poseerla definitivamente ... Y así fue en realidad ... (Sinán 1998: 129)

La erotización hace de contrapartida a cierta nostalgia mítica del agua, que es añoranza del origen y que se manifiesta en las lágrimas de la joven que quiere estar en el agua y en el líquido seminal de Ecker y del pez macho que la fecundan: 'Una noche' 'comenta Ecker' 'me confesó que estaba enamorada del mar, y [...] aseguraba que llegaría el momento en que tendría que dársele definitivamente' (Sinán 1998: 126).

La atracción que el mar ejerce sobre la joven se configura en el texto como una 'hidrotropía', en el sentido de que, como señala Bachelard (2005) y retoma Libis (2004), cada fuente de agua es un centro gravitacional para el imaginario, un ombligo, un espejo sagrado, contituye una 'hierofanía del centro' (Eliade apud Libis 2004: 215). El hidrotropismo que sufre Linda concretiza en el cuento en una cadena de acciones consecutivas dentro de un climax ascendente: ver el agua, flotar sobre ella y, finalmente, penetrar en ella. El erotismo del agua se manifiesta sobre todo en este último aspecto: en la inmersión el sujeto adquiere una pre-consciencia de la muerte como reintegración en un orden de continuidad perdido. Dicho de otro modo, el deseo sexual que Linda proyecta hacia el mar sería anhelo de una vuelta primigenia y de una reintegración en un ambiente donde el sujeto ha conocido un estado de euforia, una paradigmática ausencia de tensión. 
Objeto de amor a la vez que fuerza destructora, el agua, declinada en la imagen de la tempestad, desempeña un papel determinante en la historia a nivel simbólico 'entendida como voluntad colérica del agua' y narratológico, ya que introduce los cambios diegéticos más significativos, es decir el nacimiento de la sirenita y la desaparición de Linda. En este aspecto, Ecker recordará que 'en la noche del parto lo que más la afectó fue el explosivo fragor del huracán. Los truenos y relámpagos, el bramido del mar y los silbidos del viento le infundieron la idea de un cataclismo final en el que todo se hundía' (Sinán 1998: 128). También el desenlace está introducido por una tempestad: 'El viento había cambiado, y el mar, ligeramente picado, era un seguro anuncio de que ya estaban próximas las lluvias ... Parece que la atmósfera, cargada de corrientes magnéticas, excitó en esas noches a Linda Olsen hasta el punto de enfurecerla a cada instante' (1998: 130).

La tempestad configura el instante raro y solemne durante el cual se anuda la correspondencia extraordinaria entre la joven y el ambiente que la rodea, que desemboca en 'una comunicación interna, íntima, sustancial' (Bachelard 2005: 220). En este sentido, siguiendo la relación entre tempestad y orgasmo hipotizada por Jean Libis (2004), la lluvia refuerza en el relato la carga erótica atribuida al elemento acuático, y sostiene a nivel simbólico el ritual de fecundación de Linda.

Queda aquí reproducido el tríptico feminidad-agua-muerte, presente también en el simbolismo de la sirena; pero en este caso el papel de lo femenino es trastocado, puesto que no es Linda la que, en cualidad de sirena, induce la muerte, sino que es ella misma quien la sufre. Desde la perspectiva mitológica, Linda se configura como la hija maldita consagrada a la cólera del océano, que lleva su voz profética a la cabaña cerrada donde la joven da a luz a la sirena: el extraño nacimiento durante una tempestad nocturna marcará para siempre con su signo fatal la vida no sólo del hijo, sino también de la madre. En un clímax creciente, la pasión por el mar de Linda se convierte en necesidad vital hasta que durante una noche de tormenta Ecker se da cuenta de que la mujer ha acudido a la que ella misma define como 'cita con el mar' (130). Entre Linda y el océano se ha creado una 'simpatía colérica, una comunicación directa y reversible de las violencias' (Bachelard 2005: 221), las del elemento acuático y la de la metamorfosis de la joven.

La noche de la desgracia se describe como 'un infierno de ruidos y luces', donde 'la furia clamorosa del huracán rugía, y el viento hacía volar las cortinas’ (131). Ecker se queda dormido en la cabaña, al despertarse no ve a Linda en su cama y se lanza con la lancha de la haitiana en el mar en pos de la joven. No sabe si lo que le parece ver a ratos es Linda llevada por las olas ni cómo y cuándo se puso la boina roja en la cabeza: 'lo único que no olvido nunca' 'cuenta Ecker' 'es que debido al loco pavor de que fui presa o al ruido de la lluvia no dejé de escuchar un solo instante el doloroso alarido de Miss Olsen y un misterioso canto' (131). El deseo del agua se puede asimilar a un tropismo erótico, que se refleja en la sexualización que el mar sufre por parte de Linda. Eros y Tánatos confluyen en este elemento, lo que se nota en el hecho de que al canto de Linda se le unen sus alaridos, signo de que la forma humana de la joven se está disolviendo, dilatando y abismando. 
Al mismo tiempo, el canto de la joven que Ecker oye o cree oír al final se vuelve sinécdoque de su supuesta transformación en sirena. En el lugar liminar de la isla, lo real y lo imaginado borran sus confines, y el erotismo resulta intensificado por la presencia del ambiente acuático, ya que éste remite y amplifica su desarrollo como un espejo.

\section{La sirena como cifra de la escritura}

Ahora bien, es posible dar un paso más en el análisis. Dentro de la variabilidad de los modelos de representación que han retratado a la sirena, tanto en su tradición occidental 'homéricas y post-homéricas' como hispanoamericana, el único elemento que me parece invariable es la ambivalencia indescifrable de su aspecto, definible como complexio oppositorum [unión y coexistencia de aspectos contrarios e inconciliables]. ${ }^{12}$ Como en el caso de los monstruos híbridos 'piénsese en Medusa por ejemplo' lo que origina su poder de fascinación y terror, no es un rasgo más que otro, sino el hecho de que en ella coexisten aspectos opuestos, y no se trata simplemente de una mezcla entre elementos diferentes, sino de una interferencia sistemática entre ámbitos originariamente independientes y antagónicos.

Ese rasgo se irradia en el relato en la metamorfosis, incierta, de la protagonista 'como intercambio entre vida y muerte; es decir, disgregación de un estado para adquirir otro', y en la ambigüedad que caracteriza la escritura a raíz de las perspectivas distintas y conflictivas que la gobiernan. La figura de la sirena reúne en sí, por lo tanto, dos experiencias y dos discursos inconciliables; es decir, el sentimiento apocalíptico característico de la ciencia, encarnado en la visión de Ecker, y el misterio del origen propio del mito, sugerido por la tercera persona.

Frente a la sirenita que Linda da a luz, la explicación no declarada por el profesor del extraño engendro remonta a un episodio ocurrido después de la huida de Ben y Joe. Durante un baño entre las rocas, los dos personajes asisten a la freza de un pez hembra y a la fecundación de los huevos por parte del macho 'cubriéndola con rocío blancuzco' (Sinán 1998: 124). En el texto se lee: 'Deslumbrados por su pasión científica [...] La impresión producida por lo que había mirado, y el olor excitante de aquella mezcla ... [...] Fue un grito de la sangre que no [Lida y Ecker] pudieron sofocar ... [...] ... Y sucumbieron entre aquella sustancia gelatinosa' (1998: 124; las cursivas en el original). Con ese acontecimiento quedarían selladas las causas biológicas que explicarían la génesis de la pequeña sirena, fruto de la doble fecundación por parte del semen de Ecker junto con el del pez macho. Esta criatura se define por Ecker como un 'hecho científico' a raíz del cual 'Nada en el mundo tendría más importancia' (124). ${ }^{13}$ Otra prueba de lo afirmado reside en que Ecker habla de 'síntomas'

12 Me apropio, en este sentido, de la definición que Károly Kerényi (1994) atribuye al personaje mítico de Medusa por su hibridez constitutiva e irresolvible.

13 En este sentido, 'La boina roja' comparte con la ciencia-ficción los mecanismos de la deformación o manipulación de la realidad por parte de la ciencia, así como su proyección, en el sentido de intencionalidad y tensión, hacia el futuro. 
(126) al describir la atracción de Linda por el mar, y la atribuye a un trastorno psicológico teorizado por él y llamado 'Complejo de Glauco'.14 Finalmente, Ecker admite haber querido llevar a cabo su experimento sobre la gestación de la joven: 'Linda era para mí el único campo de experimentación' (127).

A la declaración del ictiólogo, sin embargo, se contrapone el discurso armado por la instancia heterodiegética. El nacimiento de la sirenita se define como un 'raro misterio' y 'un mito viviente'; mientras que las palabras de Linda, evocadas por la misma instancia, brinda otra explicación de su transformación:

Lo cierto es que el ambiente de la isla me hechizó transformándome, me hizo ver en mí misma a otra persona distinta de la de antes ... Para mí, pobre víctima de las inhibiciones sociales, aquello era un milagro de libertad ... Allí en la isla no había prejuicios que me ataran ... Deshice mis cadenas y me sentí a mis anchas, con ganas de gritar, de hundirme íntegra en la embriaguez del ambiente .... Todo en la isla me parecía un milagro de la Naturaleza ... Los colores del mar; el juego alegre de espumas y gaviotas; el canto de los pájaros [...] Mi cuerpo joven se deshacía en un delirio deslumbrado ... Por eso, en pleno goce de mis actos, retozaba descalza bajo la lluvia ... Quería ser una nota en el gran canto de la Naturaleza ... (Sinán 1998: 121; las cursivas en el original; la negrita es mía)

Estas líneas sugieren que Linda ha tenido acceso a una dimensión inaccesible utilizando el principio de causalidad que rige la ciencia, la del mito y de su mecanismo analógico. El íntimo contacto con la isla, 'mágica' en la poética de Sinán, y el hecho de llevar en su regazo a un ser mitad niña y mitad pez, habrían desencadenado por asociación el cambio que sufre la joven, asociación que constituye un rastro de la analogía que rige la mentalidad mítica. Siguiendo a Mircea Eliade, si Ecker ha adquirido una sabiduría en el laboratorio, y por lo tanto 'externa' y 'abstracta', Linda posee un conocimiento directo de la vida íntima de los elementos que le permite acceder al 'origen de las cosas' que se 'vive' ritualmente (2006: 22-33). Lejos de constituir un punto de fin, para la mentalidad mítica, el mar constituye un umbral inicial e iniciático detrás del cual reside otra posibilidad de vida.

En este sentido, el acto de Linda de echarse al mar durante una tempestad, clasificado por los policías como suicidio tras la declaración de Ecker, consiste más bien en la respuesta a una llamada. Parafraseando a Gaston Bachelard, las cosas, los objetos y todo el multicolor de la vegetación isleña se borra ante la joven cuando resuena el llamado del elemento acuático: el agua 'reclama de algún modo un don total, un don íntimo. El agua quiere un habitante' (Bachelard 2005: 210). Ver el mar coincide para ella con querer estar 'en él', volver a una patria. Linda escucha y oye la invitación activa de las aguas marinas, cuya fascinación, como se ha analizado, la seduce, tanto como para convertirse en el objeto de su deseo y ofrecerle el don de su intimidad. En este sentido, el personaje de Linda Olsen viene a significar ya no una antiheroína de las aguas, Ofelia panameña que

14 Inspirándose en la historia mítica, la enfermedad elaborada por el protagonista se manifiesta en 'gradaciones diversas que van desde el ligero chapuzón deleitable hasta el suicidio fatal por ahogamiento (127). En este sentido, la condición de Linda se parece a la metamorfosis real o imaginaria de la protagonista del relato de Sinán 'Todo un conflicto de sangre', quien acude al psicólogo porque está convencida de estar tansformándose en una negra, raza objeto de su repulsión (96-97). 
elige este elemento como mortaja de su suicidio, sino que la joven se concibe a sí misma como parte del agua marina, a cuyo llamado ya no puede rehuir.

Las citadas afirmaciones de Ecker y Linda parecen fundamentales ya que condensan las dos líneas de saber y poder 'es decir, las científicas y las míticas' que articulan la situación narrativa del relato. Ciencia y mito construyen dos imaginarios, y en consecuencia dos discursos, opuestos, que se sexualizan en el protagonista masculino y en el femenino que los encarnan.

Al final del relato, sin embargo, se asiste a una contaminación de lo científico por parte de lo mítico. Acosado por las preguntas del juez, Ecker aduce un 'poder ignoto' (Sinán 1998: 126) como causa última del cambio de Linda. Este sintagma parece traducir la referencia al 'raro misterio' que el narrador heterodiegético usa para describir el nacimiento de la sirenita (1998: 123), y constituye una brecha en el discurso del protagonista y en la configuración de su mundo, que hace tambalear sus certezas de raigambre racionalista y positivista. Una huella ulterior de dicha contaminación se encuentra en la ya citada comparación final entre el alma de Ecker y 'un gigantesco caracol', en donde resuenan el canto de Linda y el hondo eco del mar (132).

La confluencia de la esfera mítica en la científica nos lleva a considerar la figura-sirena más allá del plano temático y de contenido, es decir, también como cifra estructural e interpretativa del texto. La figura, en la acepción de Musil (1976), habita el espacio entre la máxima abstracción del concepto y la máxima fuerza de lo que ha sido definido mito, analogía, imaginación; al mismo tiempo, su lenguaje describe un reino intermedio entre estos dos mundos, en el que sus límites chocan y se transforman en un nuevo horizonte de sentido. La sirena es figura en el relato, además, dado que la ambigüedad acerca de su condición 'si procede de profundidades atemporales o si se originan por principios biogenéticos, en el caso de la sirenita, y si está muerta o transformada en ser marino, en el caso de Linda' parece traducir la experiencia de la modernidad conflictiva hispanoamericana y panameña, que no se puede expresar verbalmente utilizando conceptos habituales, de aquí que la sirena como figura del discurso apunta a ese tentativo de dar forma a lo que ya no se puede decir.

Lo afirmado se refleja en el límite lingüístico contra el cual choca el discurso de Ecker, quien acaba hablando de una fuerza desconocida (126) para referirse a lo acontecido a su asistente, sin definir en qué consiste este poder. Al mismo tiempo, la insuficiencia del lenguaje se remata en el desenlace del cuento, donde la voz de Linda es sustituida por su canto que Ecker persigue hasta lanzarse al mar, sigue oyendo y resuena dentro de él, pero cuyas palabras le resultan inalcanzables e incomprensibles. La alusión a 'aquel canto mezclado a la honda resonancia del mar' (132), con el cual el relato se cierra, expresa un saber cuyo contenido se queda ignorado, irreconocible e indecible, y que, sin embargo, habita a Ecker, interfiriendo con su antiguo pensamiento.

Linda por ser sirena alcanza un saber inaccesible a los demás y un secreto innombrable, y Ecker persigue el objeto fantasmal que constituye la razón imposible de hallar de su cuento. Desde esta óptica, el texto no es la relación de 
un acontecimiento, sino la aproximación a este acontecimiento, con lo cual se adhiere a la definición brindada por Maurice Blanchot como

movimiento hacia un punto, no sólo desconocido, ignorado, extraño, sino concebido de tal manera que no parece poseer, de antemano y fuera de este movimiento, realidad alguna, pero es, sin embargo, tan imperioso que de él sólo extrae el relato su atractivo, tanto así que no puede siquiera 'comenzar' antes de alcanzarlo; pero, no obstante, sólo el relato y el movimiento imprevisible del relato proporcionan el espacio donde el punto se vuelve real, poderoso y atrayente. (Sinán 1998: 13)

El movimiento del relato hacia un punto inalcanzable al que alude el filósofo encuentra su ficcionalización una vez más en la imagen conclusiva del caracol. En este, reflexiona Bachelard, 'la vida no comienza tanto lanzándose, como girando. Un impulso vital que gira’ (2012: 141), con lo cual su conformación en espiral remite a la misma dinámica del cuento que se mueve hacia un punto de huida. Al mismo tiempo, el caracol funciona, además, como metonimia de lo que se queda escondido y oculto, repetido en un segundo nivel por el relato; como 'el molusco emana su concha' (Bachelard 2012: 141), del mismo el secreto desencadena la narración y es su razón de ser. En el canto final de la joven queda sellada y desconocida la resolución del enigma que sostiene y motiva el relato; este nace de algo que aconteció y se vivió, y luego se narra; lo mismo que Ecker tuvo que vivir y sobrevivir para convertirse en el testigo que rememora y cuenta.

En el cuento, además, aflora la dimensión trágica, característica de la modernidad, Ecker, de hecho, se convierte en un héroe trágico que llega al saber de sí mismo y de las cosas del ‘otro' debilitándose, dentro de un proceso de sufrimiento que es la curación de la enfermedad del poder: el poder de imponer una razón única y un solo ethos hasta a los derrotados.

\section{El cuerpo como contradiscurso}

La compenetración entre dos saberes distintos sobre el mundo genera la ambigüedad propiamente mítica de las metamorfosis (Calvino 2015: X), ya que, a pesar de la perspectiva dominante del protagonista, la trama sugiere otra versión posible del enigma. Dicha ambivalencia rompe con un orden jerárquico unívoco y apunta a un intrincado sistema de interrelaciones donde cada nivel puede influir sobre los otros, aunque sea en medida distinta.

Por su conformación híbrida, a la sirena se le puede aplicar la reflexión de Geoffrey Stephen Kirk (2006) acerca de los centauros, sátiros y silenos. Según el filósofo, en la morfología de estos personajes se sintetiza la copresencia dicotómica entre naturaleza y cultura ' physis y nomos', ya que, por un lado, se remite al deseo y la actividad sexual que estas criaturas despertaban y, por el otro, se sugiere el miedo del ser humano a los impulsos irracionales, miedo encarnado en su aislamiento de la sociedad.

En las sirenas de Sinán, no sólo se realiza la promiscuidad prohibida entre naturaleza y cultura, sino que esta dualidad se convierte en el punto de arranque de una nueva cadena de significados, ya que a la naturaleza se le asocia lo rural, 
lo autóctono, lo mítico, lo femenino, y la cultura se declina en la tecnología, lo extranjero, lo científico, lo masculino. Al mismo tiempo, la sistemática interferencia realizada por el discurso del mito conlleva una reconfiguración de estas categorías dicotómicas, ya que a la primera se atribuye el lugar de una utopía mítica panameña frente a una antiutopía del fracaso asociada al progreso científico foráneo.

La presencia subterránea del mito y su poder corrosivo se manifiestan en una puesta en tela de juicio de un logocentrismo presente en y alcanzable por lo foráneo, en contra de un saber autóctono pre-existente a lo importado. La oposición entre foráneo y autóctono, sin embargo, se realiza no solo en el contraste atávico entre femenino y masculino ${ }^{15}$ sino también dentro de la construcción y evolución del mismo personaje femenino ya que es su cuerpo que sufre la metamorfosis.

Frente a la perspectiva dominante de Ecker 'símbolo del logocentrismo falocéntrico, a la vez que foráneo, fecundador de la mujer y, por ende, civilizador de la naturaleza inculta', el relato desarrolla un proceso subterráneo generador de un conocimiento 'otro' como perspectiva descolonizadora, a la vez que deja aflorar a un sujeto complejo, desgajado y beligerante, atrapado en múltiples contradicciones y acciones, simbólicas o materiales, de resistencia. A pesar de que Linda se rinde tácitamente ante el afán científico de Ecker, al final aboga por una sabiduría distinta que sale de las rendijas de sus definiciones, y se entrega a una metamorfosis que la deja en una forma imprecisa, haciendo tambalear, de este modo, la plataforma racionalista que rige los convencimientos del protagonista. La grieta en la narración no se abre solo y a través de la brecha en el discurso y el pensamiento de Ecker, sino que ésta es debida al cambio que sufre el cuerpo de Linda. El cuerpo de la joven, por lo tanto, se hace teatro y objeto de un proceso de des-colonización y des-centramiento de las dinámicas de saber y poder. El elemento interesante, sin embargo, reside en el hecho de que no es un sujeto en condición de subalternidad quien lleva a cabo dicho procedimiento, sino que éste se da en el interior del centro de poder, ya que Linda, por ser estadounidense, pertenece a dicho centro. La joven, además, antes de ser seductiva y mimada, es extranjera, se siente superior y rechaza con fuerza lo antillano.

En este sentido, el relato apunta a la multiplicidad conflictiva que caracteriza las líneas de saber y poder de la compleja historia panameña. Se representa la imposición de discursos y costumbres 'externos y extranjeros' que caracteriza la historia de Panamá, a partir de su nacimiento como provincia de Colombia, y luego en su condición de avasallamiento a los Estados Unidos a lo largo del siglo $\mathrm{XX}$. En cambio, la interferencia del contradiscurso mítico ínsito en el ambiente panameño podría leerse como la configuración embrional de un nuevo sujeto nacional y popular, que desembocará, después de la exacerbación de los conflictos con Estados Unidos y cuatro dictaduras, en el primer gobierno democrático con

15 Desde esta perspectiva, el relato parece anticipar y reflejar la puesta en duda de la solidaridad entre el logocentrismo y el falocentrismo relacionados a la segunda cadena simbólica expuesta, que se hará urgente para las literaturas hispanoamericanas feministas a partir de los años ochenta y noventa. 
Guillermo Endara Galimany. El 31 de diciembre de 1999, bajo la presidencia de Mireya Moscoso, Panamá asume el control total del Canal en cumplimiento de los tratados Torrijos-Carter de 1977.

La sociedad panameña se sincretiza en el cuerpo de Linda Olsen al metamorfosearse en sirena, figura híbrida que restituye transfigurada la imagen de una identidad nacional dividida desde su origen entre pertenencia política y sujeción a lo foráneo, y raíz vernácula silenciada.

A través de la transformación del cuerpo de la protagonista, el relato muestra la pugna que se da entre lo foráneo, representado por su identidad extranjera, su rechazo a lo negro, y su inicial oposición a la metamorfosis que sufre, y la fuerza seductiva de un saber ínsito en el 'raro misterio' y en el 'poder ignoto' de la naturaleza isleña, que lleva a una desjerarquización de la perspectiva dominante 'la científica de Ecker y la racista de la misma Linda', y a la asimilación gradual de lo foráneo a lo autóctono. La retórica mítica del narrador heterodiegético se insinúa en los códigos del discurso hegemónico, interfiere con ellos, rompe con su orden jerárquico unívoco, amplía las fronteras de la narración y crea un discurso alternativo, el del mito y de lo autóctono, basado en el cuestionamiento de la cultura dominante.

\section{Obras citadas}

Bachelard, Gaston, 2005. El agua y los sueños (México: Fondo de Cultura Económica).

- , 2012. La poética del espacio (México: Fondo de Cultura Económica).

Bhabha, Homi, 1994. Location of Culture (Londres y Nueva York: Routledge).

Calvino, Italo, 2015. 'Gli indistinti confini', en Metamorfosi de Ovidio (Torino: Einaudi), pp. VII-XVI.

Cannavacciuolo, Margherita, 2017. 'De sirenas tecnicizadas (I): lo científico en "La boina roja” de Rogelio Sinán', en Letterature d'America. 'Il Fantastico, il Perturbante e il Meraviglioso nelle letterature americane' 37.166-67: 69-96.

Durand, Gilbert, 2004. Las estructuras antropológicas del imaginario (México: Fondo de Cultura Económica).

Eliade, Mircea, 2006. Mito y realidad (Barcelona: Kairós).

García de Paredes, Franz, 1999 [1998]. Panamá: cuentos escogidos (Panamá: Autoridad del Canal).

Guardia, Gloria, 1974. Cuentos de Rogelio Sinán: una revisión de la vanguardia en Panamá (Panamá: Litho-Impresora Panamá).

Jesi, Furio, 1976. Mito (Barcelona: Labor).

-, 2002. 'Mito e linguaggio della collettività', en Letteratura e mito (Torino: Einaudi), pp. 33-44.

Kerényi, Károly, 1964. 'Dal mito genuino al mito tecnicizzato', en Atti del Colloquio Internazionale su 'Tecnica y casistica' (Roma: Istituto di Studi Filosofici), pp. 153-68.

- , 1994. Los dioses de los griegos (Buenos Aires: Monte Ávila).

- , 2017 [1979]. Miti e Misteri (Torino: Bollati Boringhieri).

Lévi-Strausse, Claude, 1995 [1979]. Mito y significado (Madrid: Alianza).

Libis, Jean, 2004. L'acqua e la morte (Bergamo: Moretti \& Vitali).

Menton, Seymour, 1980. 'The Red Beret. Commentary', The Spanish American Short Story: A Critical Anthology, ed. Seymour Menton (Los Angeles: University of California Press).

-, 1993 [1964]. El cuento hispanoamericano. Antología crítico-histórica (México: Fondo de Cultura Económica).

Miró Grimaldo, Rodrigo, 1999a [1950]. ‘El cuento en Panamá: reseña histórica’, en El cuento en Panamá, estudio, selección y bibliografía (Panamá: Autoridad del Canal).

- , 1999b, Itinerario de poesía en Panamá (Panamá: Autoridad del Canal).

Musil, Robert, 1976. Tagebücher (Reinbek bei Hamburg: Rowohlt).

Sinán, Rogelio, 1978. La isla mágica (Panamá: INAC). 
-, 1983 [1929; 1964]. Onda (Panama City: Ediciones Formato Dieciséis, Universidad de Panamá). - , 1998. La boina roja y otros cuentos (San José de Costa Rica: EDUCA).

Stephen Kirk, Geoffrey, 2006. El mito. Su significado y funciones en la Antigüedad y otras culturas (Barcelona: Paidós). 


